\title{
Post-surgical outcomes of patients with chronic kidney disease and end stage renal disease undergoing radical prostatectomy: 10-year results from the US National Inpatient Sample
}

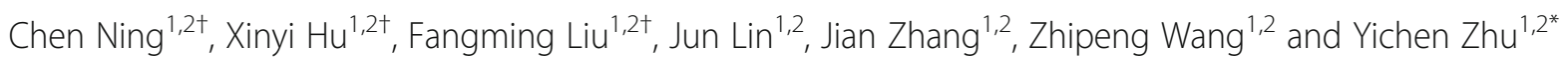

\begin{abstract}
Background: Chronic kidney disease (CKD) and end stage renal disease (ESRD) are not well characterized in prostate cancer patients. This study aimed to examine the clinical characteristics and postsurgical outcomes of patients with or without CKD and ESRD undergoing radical prostatectomy for prostate cancer.
\end{abstract}

Methods: This population-based, retrospective study used patient data from the Nationwide Inpatient Sample, the largest all-payer US inpatient care database. From 2005 to 2014, 136,790 male patients aged > 20 years diagnosed with prostate cancer and who received radical prostatectomy were included. Postoperative complications, postoperative acute kidney injury (AKI) and urinary complications, and length of hospital stay were compared between patients with or without underlying CKD and ESRD.

Results: After adjusting for relevant factors, the CKD group had a significantly higher risk of postoperative complications than the non-CKD group. In addition, the CKD group had a 5-times greater risk of postoperative AKI and urinary complications than the non-CKD group. Both CKD and ESRD groups had significantly longer hospital stays than the non-CKD group. Patients receiving RARP had a lower risk of postoperative complications than those who received open radical prostatectomy, regardless of having CKD or not. Both non-CKD and CKD patients receiving RARP had shorter hospital stays than those who received open surgery.

Conclusions: Prostate cancer patients with underlying CKD had significantly greater risk of postoperative complications, postoperative AKI and urinary complications, and longer hospital stays than those without CKD. The use of RARP significantly shortened hospital stays and reduced complications for these patients.

Keywords: Chronic kidney disease (CKD), End-stage renal disease (ESRD), Prostate cancer, Radical prostatectomy, Robot-assisted, National Inpatient Sample (NIS)

\footnotetext{
* Correspondence: yczhu82@gmail.com

${ }^{\dagger}$ Chen Ning, Xinyi Hu and Fangming Liu are contributed equally to this work and also are co-first authors

'Department of Urology, Capital Medical University Beijing Friendship Hospital, No.95 Yong'an Road, Xicheng District, Beijing 100050, China

${ }^{2}$ Beijing Key Laboratory of Tolerance Induction and Organ Protection in

Transplantation, No.95 Yong'an Road, Xicheng District, Beijing 100050, China
}

(C) The Author(s). 2019 Open Access This article is distributed under the terms of the Creative Commons Attribution 4.0 International License (http://creativecommons.org/licenses/by/4.0/), which permits unrestricted use, distribution, and reproduction in any medium, provided you give appropriate credit to the original author(s) and the source, provide a link to the Creative Commons license, and indicate if changes were made. The Creative Commons Public Domain Dedication waiver (http://creativecommons.org/publicdomain/zero/1.0/) applies to the data made available in this article, unless otherwise stated. 


\section{Background}

Acute kidney injury (AKI), estimated to occur in $21 \%$ of all hospital admissions worldwide, is associated with increased disease burden, healthcare costs, and mortality [1]. In addition to the higher risk for renal replacement therapies (RRTs) such as dialysis and kidney transplant, such patients also are at higher risk for cardiovascular events, fractures, and anemia [2]. Further, hospitalized patients with AKI are at 8-9 times greater risk of developing chronic kidney disease (CKD) and 3 times greater risk of developing end-stage renal disease (ESRD) [1]. A 2017 World Bank report estimated that the prevalence of CKD, defined in 2002 as an estimated glomerular filtration rate $(\mathrm{eGFR})<60 \mathrm{~mL} / \mathrm{min} / 1.73 \mathrm{~m}^{2}$ [3], is likely to be similar in developed and developing countries, although the etiologies and populations will differ. Estimates of prevalence range from 7 to $15 \%$. Prevalence of ESRD is shown to be much lower, about $0.03 \%$. While Western CKD and ESRD patients are often older adults with diabetes and hypertension, those in developing countries are younger, and reduced kidney function is associated with infectious diseases (e.g., HIV/AIDS, malaria, leptospirosis), herbal medicines, obstetric complications, and exposure to environmental toxins [2]. The younger patients in developing countries also have much lower access to treatment; one study found that only $5 \%$ of ESRD patients in China, India, and Nigeria have access to RRT [4].

Whatever the etiology, CKD is a significant risk factor for increased post-surgical morbidity, which includes longer hospital stays, particularly in men receiving radical prostatectomy [5-7]. One study on the impact of CKD on early postoperative outcomes in patients undergoing urological oncological surgery (including radical prostatectomy) concluded that renal dysfunction may be under-recognized in such patients, and CKD stages III, IV and $\mathrm{V}$ are independent predictors for poor 30-day postoperative outcomes [8].

Radical prostatectomy is the gold standard treatment for locally advanced prostate cancer, the most common type of cancer in men in the US $[9,10]$. Advances in detection (including prostate specific antigen [PSA] levels, magnetic resonance imaging [MRI] and a refined Gleason score) have increased the number of men presenting with localized prostate cancer [9]. A Cochrane systematic review found few clinically relevant differences in outcomes for such patients between open radical prostatectomy (ORP) and either laproscopic radical prostatectomy (LRP) or robot-assisted radical prostatectomy (RARP).

Prostate cancer-specific survival has not been addressed in controlled trials that directly compared laparoscopic radical prostatectomy and RARP with ORP [11]. Also, data regarding the clinical features and postoperative outcomes of patients who received a radical prostatectomy with CKD and ESRD are limited. Therefore, we used the comprehensive National Inpatient Sample (NIS) database from 2005 to 2014 to clarify: 1) the characteristics and 2) in-hospital outcomes of patients undergoing radical prostatectomy for prostate cancer with or without CKD or ESRD. We hypothesized that patients with baseline CKD and ESRD who underwent radical prostatectomy for prostate cancer would have higher rates of postoperative morbidities and longer hospital stays than those with intact kidney function. In addition, we also evaluated whether RARP leads to better postsurgical outcomes than open surgery in all cases and in subgroups according to kidney health status.

\section{Methods}

\section{Data source}

In this population-based, retrospective observational study, we used the NIS database, the largest all-payer, continuous US inpatient care database that includes about 8 million hospital stays each year [12]. The data elements include primary and secondary diagnoses, primary and secondary procedures, admission and discharge status, patient demographics, expected payment source, length of stay, and hospital characteristics. All patients are considered for inclusion. The most recent NIS database contains data from about 1,050 hospitals from 44 States in the US, sampled to approximate a $20 \%$ stratified sample of US community hospitals as defined by the American Hospital Association.

\section{Study population}

The primary cohort included male adults $\geq 20$ years old with prostate cancer in the US as identified in the NIS database between 2005 and 2014, with an International Classification of Diseases, Ninth Revision (ICD-9) diagnosis code of 185.0, and receipt of radical prostatectomy (ICD-9: 60.5). The study cohort was further stratified by CKD status into the following groups: non-CKD; not dialysis-dependent CKD (ICD-9: 585.1-585.5, 585.9); and ESRD (ICD-9: 585.6 or with procedure code for hemodialysis or peritoneal dialysis: $39.95,54.98$, except when dialysis was performed for AKI: 584.5 to 584.9). This approach has been used to accurately identify patients in the NIS database with CKD or ESRD $[13,14]$.

\section{Variables}

The primary endpoints were postoperative complications, postoperative AKI and urinary complications, and length of hospital stay. Postoperative complications were defined using ICD-9 codes and Clinical Classifications Software (CCS) codes. CCS is a tool developed at the Agency for Healthcare Research and Quality (AHRQ) for clustering patient diagnoses and procedures into clinically meaningful categories [15]. The following 
codes were used: cardiovascular complications: 997.1, 997.02, 997.09, 998.0, 100CCS; bleeding complications: 285.1, 998.1-998.2; pulmonary complications and pneumonia: 518.5, 518.81, 997.3, 122CCS; infection/sepsis: 998.5, 995.9; deep vein thrombosis (DVT)/ pulmonary embolism: 451.11, 451.19, 451.2, 451.81-84, 451.89, $451.9,453.40-42,453.8,453.9$, 997.2; wound complications: 998.12-998.13, 998.3, 998.5; device complications: 996.1, 996.62, 996.74; and other complications: 997.0, 997.4, 997.6-997.9, 998.2, 998.4, 998.6-998.9. Postoperative AKI and urinary complications were identified using ICD-9 codes 584, 997.5, 157CCS. Because the billing codes contained mixed diagnoses of AKI and other urinary complications that could not be separated, it was necessary to refer to a composite outcome.

Patient characteristics extracted included age, race, income, insurance status (primary payer), and surgical approach. RARP was defined by ICD-9 procedure code 17.4. Comorbidities were identified from the database using algorithms validated by Elixhauser et al. [16]. Hospital-related characteristics (bed size, location, teaching status, hospital region and annual caseload of radical prostatectomy) were extracted from the NIS database as part of the comprehensive data available for all cases.

\section{Statistical analysis}

Continuous variables are presented as mean with standard error (SE) and tested by ANOVA. Categorical variables are presented as weighted percentages and tested by Chi-square test. Logistic regression analyses and linear regression analyses were conducted to evaluate associations between the extent of kidney disease and clinical outcomes (postoperative complications, postoperative AKI and urinary complications, and length of stay). The variables that were significantly associated with the extent of kidney disease at baseline were included in multivariate regression models after adjusting for confounders. Complete case analysis was used in multivariate models. Regression models were stratified by the extent of kidney disease to evaluate associations between clinical outcomes and surgical approach (RARP versus ORP). Discharge weights were applied to the mean, SE, proportions, all testing, and regression models to account for the NIS sampling method. A 2 -sided $p$ value of $<0.05$ was considered statistically significant. Statistical analyses were performed using the SAS statistical software package, version 9.4 (SAS Institute Inc., Cary, NC, USA).

\section{Results}

\section{Study population}

Selection of the study cohort is described in Fig. 1. In 2005-2014, 462,391 male patients aged > 20 years were diagnosed with prostate cancer. Among these, 136,835 patients received radical prostatectomy. After excluding 45 cases without data for postoperative mortality or

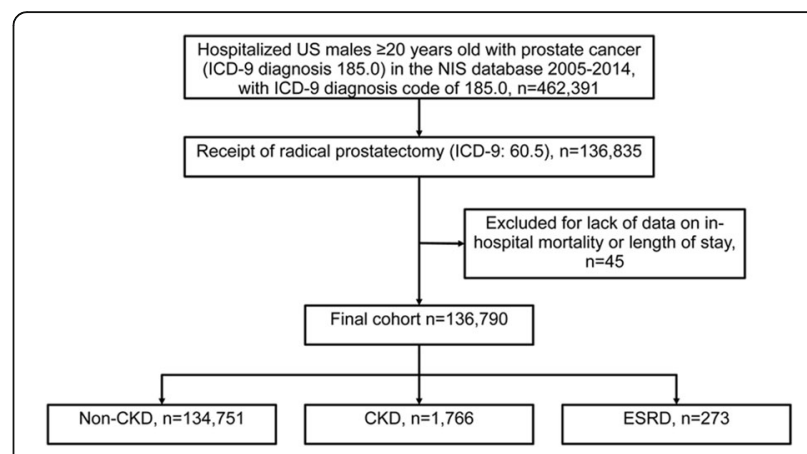

Fig. 1 Study sample selection. NIS, Nationwide Inpatient Sample; ICD-9, International Classification of Diseases, Ninth Revision; CKD, chronic kidney disease; ESRD, end-stage renal disease

length of stay, the data of 136,790 patients were available for subsequent analyses. Patients' demographics, hospital characteristics and clinical outcomes are summarized in Tables 1 and 2. Patients with differences in the extent of kidney disease were found to have significant differences in surgical approach, age, race, income by ZIP code, insurance status, location and teaching status of hospital, region of hospital, hospital caseload of radical prostatectomy, Elixhauser comorbidity score, and comorbidities, including anemia, congestive heart failure, chronic pulmonary disease, coagulopathy, depression, diabetes, hypertension, fluid/electrolyte disorders, obesity, peripheral vascular disorders and weight loss (all $p \leq 0.02$ ) (Table 1). Patients with either CKD or ESRD had longer hospital stays, greater likelihood of postoperative complications, and postoperative AKI and urinary complications than did the non-CKD group (all $p \leq 0.001$ ) (Table 2).

\section{Associations between clinical outcomes and kidney disease}

The results of regression analyses are presented in Table 3 and given in detail in Additional file 1: Table S1. The results showed that patients in the CKD and ESRD groups were at greater risk of postoperative complications than those in the non-CKD group ( $\mathrm{OR}=2.66$ and 2.83, 95\% $\mathrm{CI}=2.36-3.00$ and 2.14-3.75, respectively) (Table 3). However, after adjusting for age, race, income, insurance status, comorbidities, region, surgical approach, hospital location, teaching status, and radical prostatectomy caseload, only the CKD group had significantly higher odds of postoperative complications (adjusted odds ratio [aOR] = 1.36 , 95\% CI $=1.18-1.56)$. The CKD group had a 15.63times higher risk of postoperative AKI and urinary complications than the non-CKD group (95\% CI $=13.53-$ 18.07); these results remained significant after adjustments $(\mathrm{aOR}=5.16,95 \% \mathrm{CI}=4.32-6.17)$. The CKD and ESRD groups had significantly longer hospital stays than the non-CKD group $(\beta=1.07$ and 2.24 , respectively), and these results also remained significant after adjustments ( $\beta=0.25$ and 0.98 , respectively) (Table 3 ). 
Table 1 Descriptive statistics of surgical approaches, demographic data, and hospital characteristics by extent of kidney disease

\begin{tabular}{|c|c|c|c|c|c|}
\hline$\underline{\text { Variables }}$ & All patients $(N=136,790)$ & Non-CKD $(n=134,751)$ & CKD $(n=1,766)$ & $\operatorname{ESRD}(n=273)$ & $p$-value \\
\hline Surgical approach & & & & & $<.001$ \\
\hline Robot-assisted & $58703(43)$ & $57614(42.8)$ & $957(54.1)$ & $132(48.5)$ & \\
\hline Open & $78087(57)$ & $77137(57.2)$ & $809(45.9)$ & $141(51.5)$ & \\
\hline \multicolumn{6}{|l|}{ Demographic data } \\
\hline Age & $61.37 \pm 0.05$ & $61.34 \pm 0.05$ & $64.5 \pm 0.18$ & $60.34 \pm 0.4$ & $<.001$ \\
\hline Race & & & & & $<.001$ \\
\hline Missing & $22526(16.4)$ & $22230(16.5)$ & $265(14.9)$ & $31(11.3)$ & \\
\hline White & $87803(64.3)$ & $86795(64.5)$ & $904(51.3)$ & $104(38.2)$ & \\
\hline Black & $13597(9.9)$ & $13078(9.7)$ & $423(23.9)$ & $96(35.3)$ & \\
\hline Hispanic & $6802(5)$ & $6685(4.9)$ & $92(5.2)$ & $25(9)$ & \\
\hline Other & $6062(4.4)$ & $5963(4.4)$ & $82(4.6)$ & $17(6.2)$ & \\
\hline Income & & & & & $<.001$ \\
\hline Missing & $3506(2.6)$ & $3469(2.6)$ & $32(1.8)$ & $5(1.9)$ & \\
\hline 0-25th percentile & $24745(18)$ & $24257(18)$ & $408(23.2)$ & $80(29.4)$ & \\
\hline 26th to 50th percentile & $30884(22.5)$ & $30363(22.5)$ & $447(25.4)$ & $74(27.1)$ & \\
\hline 51st to 75 th percentile & $35469(25.9)$ & $34987(26)$ & $422(23.9)$ & $60(21.8)$ & \\
\hline 76th to 100th percentile & $42186(31)$ & $41675(31)$ & $457(25.7)$ & $54(19.8)$ & \\
\hline Insurance status & & & & & $<.001$ \\
\hline Missing & $256(0.2)$ & $254(0.2)$ & $1(0.1)$ & $1(0.4)$ & \\
\hline Medicare/Medicaid & $45803(33.5)$ & $44683(33.1)$ & $938(53.2)$ & $182(66.3)$ & \\
\hline Private/HMO & $84938(62.1)$ & $84089(62.4)$ & $765(43.2)$ & $84(31.1)$ & \\
\hline Self-pay/no-charge/other & $5793(4.2)$ & $5725(4.2)$ & $62(3.5)$ & $6(2.2)$ & \\
\hline \multicolumn{6}{|l|}{ Hospital characteristics } \\
\hline Bed size & & & & & .27 \\
\hline Missing & $720(0.5)$ & $703(0.5)$ & $15(0.8)$ & $2(0.8)$ & \\
\hline Small & $14495(10.3)$ & $14280(10.3)$ & $191(10.4)$ & $24(8.3)$ & \\
\hline Medium & $28040(20.7)$ & $27590(20.67)$ & $397(22.9)$ & $53(19.7)$ & \\
\hline Large & $93535(68.5)$ & $92178(68.5)$ & $1163(65.9)$ & $194(71.3)$ & \\
\hline Location and teaching status & & & & & .02 \\
\hline Missing & $720(0.5)$ & $703(0.5)$ & $15(0.8)$ & $2(0.8)$ & \\
\hline Rural & $6294(4.6)$ & $6203(4.6)$ & $84(4.7)$ & $7(2.5)$ & \\
\hline Urban nonteaching & $40144(29.1)$ & $39571(29.1)$ & $518(29.3)$ & 55 (19.6) & \\
\hline Urban teaching & $89632(65.9)$ & $88274(65.8)$ & $1149(65.2)$ & $209(77.2)$ & \\
\hline Region & & & & & $<.001$ \\
\hline Northeast & $25341(19.2)$ & $25046(19.3)$ & $237(13.9)$ & $58(22.1)$ & \\
\hline Midwest & $32953(24.4)$ & $32348(24.3)$ & $543(30.9)$ & $62(22.5)$ & \\
\hline South & $48141(34.7)$ & $47480(34.7)$ & $567(31.8)$ & $94(34)$ & \\
\hline West & $30355(21.8)$ & $29877(21.7)$ & $419(23.4)$ & $59(21.4)$ & \\
\hline Radical prostatectomy caseload ${ }^{a}$ & & & & & $<.001$ \\
\hline 0-25th percentile & $32941(24.1)$ & $32264(24)$ & $606(34.6)$ & $71(25.5)$ & \\
\hline 26th to 50th percentile & $35214(25.7)$ & $34646(25.7)$ & $491(27.8)$ & $77(28.1)$ & \\
\hline 51st to 75 th percentile & $34151(24.8)$ & $33741(24.9)$ & 347 (19.6) & $63(23.4)$ & \\
\hline 76th to 100th percentile & $34484(25.3)$ & $34100(25.4)$ & $322(18)$ & $62(23.1)$ & \\
\hline
\end{tabular}


Table 1 Descriptive statistics of surgical approaches, demographic data, and hospital characteristics by extent of kidney disease (Continued)

\begin{tabular}{|c|c|c|c|c|c|}
\hline Variables & All patients $(N=136,790)$ & Non-CKD $(n=134,751)$ & CKD $(n=1,766)$ & $\operatorname{ESRD}(n=273)$ & $p$-value \\
\hline Elixhauser comorbidity score ${ }^{b}$ & & & & & $<.001$ \\
\hline 0-25th percentile & $48823(35.7)$ & $48811(36.2)$ & $11(0.6)$ & $1(0.4)$ & \\
\hline 26th to 50th percentile & $50502(36.9)$ & $50366(37.4)$ & $131(7.4)$ & $5(1.8)$ & \\
\hline 51st to 75 th percentile & $25410(18.6)$ & $24894(18.5)$ & $471(26.6)$ & $45(16.4)$ & \\
\hline 76th to 100th percentile & $12055(8.8)$ & $10680(7.8)$ & $1153(65.3)$ & $222(81.4)$ & \\
\hline Anemia & $4774(3.5)$ & $4362(3.2)$ & $287(16.2)$ & $125(45.8)$ & $<.001$ \\
\hline Congestive heart failure & $820(0.6)$ & $718(0.5)$ & $82(4.7)$ & $20(7.3)$ & $<.001$ \\
\hline Chronic pulmonary disease & $10580(7.7)$ & $10310(7.7)$ & $241(13.8)$ & $29(10.7)$ & $<.001$ \\
\hline Coagulopathy & $879(0.6)$ & $815(0.6)$ & $56(3.2)$ & $8(2.9)$ & $<.001$ \\
\hline Depression & $5459(4.0)$ & $5353(3.9)$ & $93(5.3)$ & $13(4.8)$ & .02 \\
\hline Diabetes & $17106(12.5)$ & $16405(12.2)$ & $602(33.9)$ & $99(36.4)$ & $<.001$ \\
\hline Hypertension & $66931(50.9)$ & $65151(48.3)$ & $1521(86.1)$ & $259(94.8)$ & $<.001$ \\
\hline Fluid/electrolyte disorders & $3755(2.8)$ & $3449(2.5)$ & $254(14.4)$ & $52(19.3)$ & $<.001$ \\
\hline Obesity & $9411(6.9)$ & $9101(6.8)$ & $279(15.7)$ & $31(11.5)$ & $<.001$ \\
\hline Peripheral vascular disorders & $1465(1.1)$ & $1368(1.0)$ & $89(5.0)$ & $8(3.1)$ & $<.001$ \\
\hline Weight loss & $230(0.2)$ & $209(0.2)$ & $18(1.0)$ & $3(1.0)$ & $<.001$ \\
\hline
\end{tabular}

Continuous variables are presented as mean \pm standard error

Categorical variables are presented as unweighted counts (weighted percentage)

Percentages may not add up due to missing values

CKD chronic kidney disease, ESRD end stage renal disease

${ }^{1}$ Chi-square $p$-values are given for categorical variables, and Wald F-test $p$-values for continuous variables

${ }^{a}$ Hospital annual radical prostatectomy caseload was defined using quartiles $\left(Q_{1}=22, Q_{2}=69, Q_{3}=169\right)$

${ }^{b}$ Elixhauser comorbidity score was defined using quartiles $\left(Q_{1}=0, Q_{2}=1, Q_{3}=2\right)$

\section{Associations between clinical outcomes and type of surgery}

We also conducted kidney disease-stratified regression analyses to compare types of surgery (RARP versus ORP) as shown in Table 4. Patients receiving RARP had lower risk of postoperative complications than those who received ORP, after adjusting for relevant factors [all patients: aOR $(95 \% \mathrm{CI})=0.55(0.51-0.60)$; non-CKD: aOR $(95 \% \mathrm{CI})=0.54(0.50-0.60) ; \mathrm{CKD}: \mathrm{aOR}(95 \% \mathrm{CI})=0.65$ $(0.50-0.85)$; ESRD: aOR $(95 \% \quad \mathrm{CI})=0.53 \quad(0.21-0.91)]$

Table 2 Descriptive statistics of clinical outcomes by extent of kidney disease

\begin{tabular}{|c|c|c|c|c|c|}
\hline Clinical outcomes & All patients $(\mathrm{N}=136,790)$ & Non-CKD $(n=134,751)$ & CKD $(n=1,766)$ & $\operatorname{ESRD}(n=273)$ & $p$-value \\
\hline Length of stay & $2.11 \pm 0.02$ & $2.09 \pm 0.02$ & $3.16 \pm 0.11$ & $4.33 \pm 0.41$ & $<.001$ \\
\hline Postoperative complication & $12434(9.1)$ & $12011(8.9)$ & $364(20.6)$ & 59 (21.6) & $<.001$ \\
\hline In-hospital mortality & $55(0.04)$ & $51(0.04)$ & $2(0.1)$ & $2(0.7)$ & $<.001$ \\
\hline Cardiovascular complications & $943(0.7)$ & $889(0.7)$ & $46(2.7)$ & $8(3)$ & $<.001$ \\
\hline Bleeding complications & $7974(5.8)$ & $7708(5.7)$ & $230(13)$ & $36(13.2)$ & $<.001$ \\
\hline Pulmonary complications & $1251(0.9)$ & $1158(0.9)$ & $75(4.2)$ & $18(6.5)$ & $<.001$ \\
\hline Infection/sepsis & $303(0.2)$ & $273(0.2)$ & $22(1.2)$ & $8(3)$ & $<.001$ \\
\hline DVT / Pulmonary embolism & $204(0.2)$ & $189(0.1)$ & $13(0.8)$ & $2(0.7)$ & $<.001$ \\
\hline Wound complications & $694(0.5)$ & $662(0.5)$ & $24(1.3)$ & $8(2.9)$ & $<.001$ \\
\hline Device complications & $28(0.02)$ & $20(0.02)$ & $1(0.1)$ & $7(2.5)$ & $<.001$ \\
\hline Other complications & $4689(0.08)$ & $4575(3.4)$ & $102(5.8)$ & $12(4.4)$ & $<.001$ \\
\hline Postoperative AKI and urinary complications ${ }^{a}$ & $1999(1.5)$ & $1704(1.3)$ & $295(16.4)$ & - & $<.001$ \\
\hline
\end{tabular}

Continuous variables are presented as mean \pm standard error

Categorical variables are presented as unweighted counts (weighted percentage)

CKD chronic kidney disease, ESRD end stage renal disease, DVT deep vein thrombosis, AKI acute kidney injury

${ }^{1}$ Chi-square $p$-values are given for categorical variables, and Wald F-test $p$-values for continuous variables

${ }^{a}$ The ESRD group was not included in the analysis of postoperative AKI and urinary complications 
Table 3 Associations between clinical outcomes and extent of kidney disease

\begin{tabular}{|c|c|c|c|c|c|c|c|c|}
\hline & \multicolumn{3}{|c|}{ Postoperative complication } & \multicolumn{3}{|c|}{ Postoperative $\mathrm{AKI}$ and urinary complications ${ }^{\mathrm{b}}$} & \multicolumn{2}{|c|}{ Length of stay } \\
\hline & $\overline{n(\%)}$ & OR $(95 \% \mathrm{Cl})$ & $\mathrm{aOR}(95 \% \mathrm{Cl})^{\mathrm{a}}$ & $\overline{n(\%)}$ & OR $(95 \% \mathrm{Cl})$ & $\mathrm{aOR}(95 \% \mathrm{Cl})^{\mathrm{a}}$ & $\beta \pm S E$ & $\beta \pm S E^{a}$ \\
\hline $\begin{array}{l}\text { Non-CKD } \\
(n=134,751)\end{array}$ & $12,011(8.9)$ & Reference & Reference & $1,704(1.3)$ & Reference & Reference & Reference & Reference \\
\hline CKD $(n=1,766)$ & $364(20.6)$ & $2.66(2.36-3.00)$ & $1.36(1.18-1.56)$ & $295(16.4)$ & $15.63(13.53-18.07)$ & $5.16(4.32-6.17)$ & $1.07 \pm 0.11$ & $0.25 \pm 0.1$ \\
\hline $\operatorname{ESRD}(n=273)$ & $59(21.6)$ & $2.83(2.14-23.75)$ & $1.35(0.97-1.87)$ & - & - & - & $2.24 \pm 0.41$ & $0.98 \pm 0.4$ \\
\hline
\end{tabular}

Significant values are in bold

$A K I$ acute kidney injury, OR odds ratio, $C I$ confidence interval, $a O R$ adjusted odds ratio, SE standard error, $\beta$ beta-coefficient, CKD chronic kidney disease, ESRD endstage renal disease

a Multivariate analyses were adjusted for significant baseline characteristics, including surgical approach, age, race, income, insurance status, hospital location and teaching status, region, radical prostatectomy caseload, and all comorbidities

${ }^{\mathrm{b}}$ The ESRD group was not included in the model of postoperative AKI and urinary complications

(Table 4). In the CKD group, those receiving RARP had lower risk of postoperative AKI and urinary complications than those receiving open surgery $(\mathrm{OR}=0.75,95 \% \mathrm{CI}=$ $0.57-0.98$ ); however, the results did not remain significant after adjustments (Table 4). After adjustments, non-CKD and CKD patients receiving RARP had shorter hospital stays than those who received open surgery (all patients: $\beta=-0.75$; non-CKD: $\beta=-0.75$; CKD: $\beta=-0.95$ ) (Table 4).

\section{Discussion}

In the present study, we examined the clinical characteristics and postsurgical outcomes of patients with or without CKD and ESRD undergoing radical prostatectomy for prostate cancer. We found that patients with underlying CKD had significantly increased risk of postoperative complications, including more than 5 -times the risk of postoperative AKI and urinary complications than those without CKD. CKD patients also had longer hospital stays. In addition, comparison of outcomes by type of surgery was performed to further assess the possible benefit of robotic surgery. Those who received RARP had significantly lower risk of postoperative complications than those who received ORP, regardless of kidney health status. The use of RARP was associated with significantly shortened hospital length of stay only for CKD and non-CKD patients.

Other authors have compared postoperative outcomes in patients with CKD undergoing urological oncological surgery. In one study, which included 8,610 men receiving radical prostatectomy, 3,330 (38.7\%) had no CDK and 5,280 (61.3\%) had some level of CDK (ESRD not included). In the overall cohort, CKD was associated with

Table 4 Association between surgical approach and clinical outcomes by extent of kidney disease

\begin{tabular}{|c|c|c|c|c|c|c|c|c|c|}
\hline & \multirow[t]{2}{*}{$\begin{array}{l}\text { Surgical } \\
\text { approach }\end{array}$} & \multicolumn{3}{|c|}{ Postoperative complication } & \multicolumn{3}{|c|}{$\begin{array}{l}\text { Postoperative AKI and } \\
\text { urinary complications }\end{array}$} & \multicolumn{2}{|l|}{ Length of stay } \\
\hline & & $\mathrm{n}(\%)$ & OR $(95 \% \mathrm{Cl})$ & $\mathrm{aOR}(95 \% \mathrm{Cl})^{\mathrm{a}}$ & n (\%) & OR $(95 \% \mathrm{Cl})$ & $\mathrm{aOR}(95 \% \mathrm{Cl})^{\mathrm{a}}$ & $\beta \pm S E$ & $\beta \pm S E^{a}$ \\
\hline \multirow[t]{2}{*}{$\begin{array}{l}\text { All patients } \\
(\mathrm{N}=136,790)\end{array}$} & Open & $\begin{array}{l}8,665 \\
(6.3)\end{array}$ & Reference & Reference & $\begin{array}{l}1,140 \\
(0.8)\end{array}$ & Reference & Reference & Reference & Reference \\
\hline & Robot-assisted & $\begin{array}{l}3,769 \\
(2.8)\end{array}$ & $0.55(0.50-0.60)$ & $0.55(0.51-0.60)$ & $\begin{array}{l}859 \\
(0.6)\end{array}$ & $1.01(0.90-1.13)$ & $1.09(0.98-1.23)$ & $-0.77 \pm 0.04$ & $-0.75 \pm 0.03$ \\
\hline \multirow[t]{2}{*}{$\begin{array}{l}\text { Non-CKD } \\
(n=134,751)\end{array}$} & Open & $\begin{array}{l}8,432 \\
(6.3)\end{array}$ & Reference & Reference & $\begin{array}{l}987 \\
(0.7)\end{array}$ & Reference & Reference & Reference & Reference \\
\hline & Robot-assisted & $\begin{array}{l}3,579 \\
(2.7)\end{array}$ & $0.54(0.49-0.59)$ & $0.54(0.50-0.60)$ & $\begin{array}{l}717 \\
(0.5)\end{array}$ & $0.98(0.87-1.09)$ & $1.08(0.96-1.22)$ & $-0.78 \pm 0.04$ & $-0.75 \pm 0.03$ \\
\hline \multirow[t]{2}{*}{$\begin{array}{l}\text { CKD } \\
n=1,766)\end{array}$} & Open & $\begin{array}{l}197 \\
(11.2)\end{array}$ & Reference & Reference & $\begin{array}{l}153 \\
(8.7)\end{array}$ & Reference & Reference & Reference & Reference \\
\hline & Robot-assisted & $\begin{array}{l}167 \\
(9.5)\end{array}$ & $0.66(0.52-0.84)$ & $0.65(0.50-0.85)$ & $\begin{array}{l}142 \\
(8.0)\end{array}$ & $0.75(0.57-0.98)$ & $0.83(0.62-1.12)$ & $-1.32 \pm 0.24$ & $-0.95 \pm 0.18$ \\
\hline \multirow[t]{2}{*}{$\begin{array}{l}\text { ESRD } \\
(n=273)\end{array}$} & Open & $\begin{array}{l}36 \\
(13.2)\end{array}$ & Reference & Reference & & - & - & Reference & Reference \\
\hline & Robot-assisted & $\begin{array}{l}23 \\
(8.4)\end{array}$ & $0.61(0.34-1.09)$ & $0.43(0.21-0.91)$ & & & & $-0.34 \pm 0.84$ & $-0.66 \pm 0.71$ \\
\hline
\end{tabular}

Significant values are in bold

$A K I$ acute kidney injury, $O R$ odds ratio, $a O R$ adjusted odds ratio, $C l$ confidence interval, SE standard error, $\beta$ beta-coefficient; $C K D$ chronic kidney disease, ESRD end stage renal disease

${ }^{a}$ Multivariate analyses were adjusted for significant baseline characteristics, including age, race, income, insurance status, hospital location and teaching status, region, radical prostatectomy caseload, and all comorbidities

${ }^{\mathrm{b}}$ The ESRD group was not included in the model of postoperative AKI and urinary complications 
increased odds of postoperative complications and longer hospital stays $(p<0.05)$, although the risk of complications was lower in prostate cancer patients than in those receiving other types of surgery (e.g., partial or radical nephrectomy or open radical cystectomy). Those authors noted that the prostate cancer patients, $65.4 \%$ of the total cohort, were healthier than the other types of patients included [8]. We also found that CKD was associated with significantly more postoperative complications and longer hospital stays relative to those with intact kidney function.

The risk of postoperative AKI after prostate surgery has been a subject of recent focus. While severe AKI after prostatectomy appears to be infrequent, transurethral resection of the prostate and transurethral rhabdomyolysis appear to increase the risk [17]. Propensity score matching analysis found that RARP had better outcomes than retropubic radical prostatectomy in terms of blood loss and hospital length of stay $(p<$ $0.001)$. It also was associated with a much lower incidence of AKI (5.5\% versus 10.4\%, $p=0.044)$ [18]. Previous studies did not appear to take into account existing CKD. In the present study, patients with CKD had more postoperative AKI and urinary complications than did non-CKD patients. We must also point out that the overall incidence of AKI might be underestimated in the present study. AKI involves small changes in creatinine and urinary output. Identifying AKI using billing codes has low sensitivity, which may result in bias [19]. Grams et al. (2014) [19] compared billing code-identified AKI with the 2012 Kidney Disease Improving Global Outcomes (KDIGO) creatinine-based criteria and an approximation of the 2012 KDIGO creatinine- and urine output- based criteria in a subset with available outpatient data. It has been concluded that the use of billing codes to identify AKI has low sensitivity compared with the current KDIGO consensus definition, especially when the urine output criterion is included, and results in the identification of a more severe phenotype [19].

In the present study, we conducted additional analyses to compare results by type of surgery. A previous study of NIS data from 2001 to 2007 found that patients who received minimally invasive surgery (as compared to open surgery) had a shorter length of stay $(\mathrm{OR}=0.61$, 95\% CI: $0.54-0.69, p<0.001)$ [20]. Similarly, one study from Japan compared 89 consecutive cases of RARP with 105 cases of open surgery; those receiving RARP had fewer postoperative infections, although the results were not significant [21]. A previous meta-analysis of two single-setting studies $(n=446)$ found slight improvement in certain postoperative outcomes of RARP versus ORP and concluded that this "probably" was associated with reduced length of hospital stay [11]. A 2018 review and meta-analysis of RARP versus ORP in 19 studies
( $n=16,830)$ performed around the world found inconsistent results, although RARP was associated with better results in terms of blood loss, transfusion, nervesparing, recovery of urinary continence, and recovery of erectile function [22]. In another recent study, Saika et al. (2018) [23] reported the use of RARP in high-risk locally advanced prostate cancer as an option providing optimal outcomes; the included studies reported acceptable perioperative and oncological outcomes as well as improved survival. In addition, advantages of RARP, including tissue magnification and recognition, and tridimensional vision, are shown to aid the recovery of urinary continence [23]. Unlike these previous studies, the present study compared RARP to ORP according to patients' kidney function. All had lower rates of postoperative complications, and non-CKD and CKD patients had shorter hospital stays. The better results of RARP might also be explained by the reasons mentioned above. However, confounding by indication could not be ruled out given the design of the present study. Thus, readers are advised to interpret these results with caution.

\section{Limitations}

The present study has several limitations. First, patients with CKD or ESRD were identified using ICD-9-CM codes. Although the ICD-9 diagnosis for CKD is highly specific, its sensitivity is only around $80 \%$ [24]. Therefore, some patients with milder degrees of CKD may have been misclassified as not having CKD. Comorbidities and postoperative complications were identified using ICD-9 and CCS codes, by which the severity of comorbidities could not be indicated. As mentioned above, the use of billing codes to identify AKI has low sensitivity, which may result in bias. Due to significant overlap between patients, the (non-ESRD) CKD cohort could not be separated into individual groups based on stages, and management of CKD could not be accounted for because information was not included in the database. The NIS database also did not include data on prostatespecific antigen (PSA) levels, Gleason scores and prostate cancer management; complications definitions and management; the surgical course or alternate treatments (e.g., use of contrast agents and non-surgical management options for prostate cancer (e.g., chemotherapy, radiotherapy, or hormone therapy) that may independently contribute to adverse outcomes. In addition, other possible confounding variables not collected by NIS were necessarily excluded from our analyses. Finally, since we did not include follow-up data after discharge, we were unable to evaluate late morbidity and oncological outcomes. Despite these limitations, the NIS data provided a 10-year history of representative US patients undergoing radical prostatectomy and their post-surgical outcomes with or without underlying CKD and ESRD, 
representing an important strength of the present study and adding credence to the results.

\section{Conclusion}

In conclusion, patients with CKD and ESRD undergoing radical prostatectomy for prostate cancer have a greater likelihood of postoperative morbidities and longer hospital stays than those without CKD. Patients receiving radical prostatectomy should be carefully evaluated for kidney dysfunction, as this factor significantly affects post-surgical outcomes. RARP appears to have better outcomes than ORP in terms of postoperative complications and length of stay; however, these results need to be further confirmed. Further investigation and vigilance in treating the CKD/ESRD population, and evaluating the possible influence of CKD stages, is highly warranted.

\section{Additional file}

Additional file 1: Table S1. Multivariate models of clinical outcomes by extent of kidney disease, demographic characteristics, hospital characteristics, and comorbidities (DOCX $23 \mathrm{~kb}$ )

\begin{abstract}
Abbreviations
AHRQ: Agency for Healthcare Research and Quality; AKI: Acute kidney injury; CCS: Clinical classifications software; CKD: Chronic kidney disease; DVT: Deep vein thrombosis; eGFR: Estimated glomerular filtration rate; ESRD: End-stage renal disease; HCUP: Healthcare cost and utilization project; KDIGO: Kidney disease improving global outcomes; LRP: Laparoscopic radical prostatectomy; MRI: Magnetic resonance imaging; NIS: National Inpatient Sample; ORP: Open radical prostatectomy; PSA: Prostate specific antigen; RARP: Robot-assisted radical prostatectomy;i RRT: Renal replacement therapy
\end{abstract}

\section{Acknowledgements}

None.

\section{Authors' contributions}

$\mathrm{CN}$ : Conception and design; Analysis and interpretation of data; Drafting of the manuscript; Final approval of the manuscript; literature research; Obtaining funding. XYH: Acquisition of data; Drafting of the manuscript; Final approval of the manuscript; statistical analysis; literature research. FML: Acquisition of data; Drafting of the manuscript; Final approval of the manuscript; statistical analysis. $J \mathrm{~L}$ : Analysis and interpretation of data; Critical revision of the manuscript; Final approval of the manuscript. JZ: Analysis and interpretation of data; Critical revision of the manuscript; Final approval of the manuscript; literature research. ZPW: Acquisition of data; Critical revision of the manuscript; Final approval of the manuscript. YCZ: Conception and design; Analysis and interpretation of data; Critical revision of the manuscript; Final approval of the manuscript; guarantor of integrity of the entire study; Obtaining funding. We confirm that all authors have read and approved of the final version.

\section{Funding}

This study was supported by National Natural Science Foundation of China (Grant No.81700671 and No. 81801437) and Beijing Hospitals Authority Youth Programme, Code: QMS20180104, in the study design, data collection, analysis and interpretation, and the manuscript writing

\section{Availability of data and materials}

The datasets used and/or analyzed during the current study are available from the corresponding author on reasonable request.

\section{Ethics approval and consent to participate}

We obtained the certificate number HCUP-4V39150IU from the Healthcare Cost and Utilization Project (HCUP) and conformed to the data-use agreement for the NIS as received from HCUP. The Institutional Review Board (IRB)/Bioethics Committee of Beijing Friendship Hospital, Capital Medical University approved the study design and no consent was required to use the de-identified NIS patient data.

Consent for publication

Not applicable.

\section{Competing interests}

The authors declare that they have no competing interests.

Received: 3 January 2019 Accepted: 4 July 2019

Published online: 23 July 2019

References

1. Bouchard J, Mehta RL. Acute kidney injury in Western countries. Kidney Dis (Basel). 2016;2:103-10. https://doi.org/10.1159/000445091.

2. Anand S, Thomas B, Remuzzi G, Riella M, Nahas ME, Naicker S, et al. Chapter 13: kidney disease. In: Prabhakaran D, Anand S, Gaziano TA, Mbanya JC, Wu $Y$, Nugent R, editors. Cardiovascular, respiratory, and related disorders. 3rd ed. The International Bank for Reconstruction and Development / The World Bank: Washington (DC); 2017. p. Chapter 13. Available at: https:// www.ncbi.nlm.nih.gov/books/NBK525140/.

3. National Kidney Foundation. KDOQI clinical practice guidelines for chronic kidney disease evaluation. Am J Kidney Dis. 2002:39(2 Suppl 1):S1-266.

4. Anand S, Bitton A, Gaziano T. The gap between estimated incidence of end-stage renal disease and use of therapy. PLoS One. 2013;8:e72860. https://doi.org/10.1371/journal.pone.0072860.

5. Mooney JF, Ranasinghe I, Chow CK, Perkovic V, Barzi F, Zoungas S, et al. Preoperative estimates of glomerular filtration rate as predictors of outcome after surgery: a systematic review and meta-analysis. Anesthesiology. 2013; 118:809-24. https://doi.org/10.1097/ALN.0b013e318287b72c.

6. Go AS, Chertow GM, Fan D, McCulloch CE, Hsu CY. Chronic kidney disease and the risks of death, cardiovascular events, and hospitalization. N Engl J Med. 2004;351:1296-305. https://doi.org/10.1056/NEJMoa041031.

7. Tollefson MK, Booriian SA, Gettman MT, Rangel LJ, Bergstralh EJ, Karnes RJ. Preoperative estimated glomerular filtration rate predicts overall mortality in patients undergoing radical prostatectomy. Urol Oncol. 2013;31:1483-8. https://doi.org/10.1016/j.urolonc.2012.03.014

8. Schmid M, Ravi P, Abd-El-Barr AE, Klap J, Sammon JD, Chang SL, et al. Chronic kidney disease and perioperative outcomes in urological oncological surgery. Int J Urol. 2014;21:1245-52. https://doi.org/10.1111/ iju.12563.

9. Faria EF, Chapin BF, Muller RL, Machado RD, Reis RB, Matin SF. Radical prostatectomy for locally advanced prostate cancer: current status. Urology. 2015;86:10-5. https://doi.org/10.1016/j.urology.2015.03.012.

10. DeSantis CE, Lin CC, Mariotto AB, Siegel RL, Stein KD, Kramer JL, et al Cancer treatment and survivorship statistics, 2014. CA Cancer J Clin. 2014;64 252-71. https://doi.org/10.3322/caac.21235.

11. Hic D, Evans SM, Allan CA, Jung JH, Murphy D, Frydenberg M. Laparoscopic and robot-assisted vs open radical prostatectomy for the treatment of localized prostate cancer: a Cochrane systematic review. BJU Int. 2018;121: 845-53. https://doi.org/10.1111/bju.14062

12. Introduction to the Nationwide Inpatient Sample (NIS). Rockville, MD: Healthcare Cost and Utilization Project (HCUP) sponsored by the Agency for Healthcare Research and Quality; 2008. Available at: https://www.hcup-us. ahrq.gov/db/nation/nis/NIS_Introduction_2008.jsp. Accessed 13 July 2016.

13. Gupta T, Harikrishnan P, Kolte D, Khera S, Subramanian KS, Mujib M, et al. Trends in management and outcomes of ST-elevation myocardial infarction in patients with end-stage renal disease in the United States. Am J Cardiol. 2015;115:1033-41. https://doi.org/10.1016/j.amjcard.2015.01.529.

14. Gupta T, Kolte D, Khera S, Goel K, Aronow WS, Cooper HA, et al. Management and outcomes of ST-segment elevation myocardial infarction in US renal transplant recipients. JAMA Cardiol. 2017;2:250-8. https://doi. org/10.1001/jamacardio.2016.5131.

15. Healthcare Cost and Utilization Project (HCUP). HCUP CCS Fact Sheet. Rockville: Agency for Healthcare Research and Quality; 2012. Available at: www.hcup-us.ahrq.gov/toolssoftware/ccs/ccsfactsheet.jsp

16. Elixhauser A, Steiner C, Harris DR, Coffey RM. Comorbidity measures for use with administrative data. Med Care. 1998;36:8-27. 
17. Costalonga EC, Costa E, Silva VT, Caires R, Hung J, Yu L, et al. Prostatic surgery associated acute kidney injury. World J Nephrol. 2014;3:198-209. https://doi.org/10.5527/wjn.v3.i4.198.

18. Joo EY, Moon YJ, Yoon SH, Chin JH, Hwang JH, Kim YK. Comparison of acute kidney injury after robot-assisted laparoscopic radical prostatectomy versus retropubic radical prostatectomy: A propensity score matching analysis. Medicine (Baltimore). 2016;95:e2650. https://doi.org/10.1097/MD. 0000000000002650

19. Grams ME, Waikar SS, MacMahon B, Whelton S, Ballou SH, Coresh J. Performance and limitations of administrative data in the identification of AKI. Clin K Am Soc Nephrol. 2014;9. https://doi.org/10.2215/CJN.07650713.

20. Trinh QD, Bianchi M, Sun M, Sammon J, Schmitges J, Shariat SF, et al. Discharge patterns after radical prostatectomy in the United States of America. Urol Oncol. 2013;31:1022-32. https://doi.org/10.1016/j.urolonc.2 011.10.007.

21. Shigemura K, Tanaka K, Yamamichi F, Muramaki M, Arakawa S, Miyake H, et al. Comparison of postoperative infection between robotic-assisted laparoscopic prostatectomy and open radical prostatectomy. Urol Int. 2014; 92:15-9. https://doi.org/10.1159/000350334.

22. Du Y, Long Q, Guan B, Mu L, Tian J, Jiang Y, et al. Robot-assisted radical prostatectomy is more beneficial for prostate cancer patients: A system review and meta-analysis. Med Sci Monit. 2018;24:272-87. https://doi.org/1 0.12659/MSM.907092.

23. Saika T, Miura N, Fukumoto T, Yanagihara Y, Miyauchi Y, Kikugawa T. Role of robot-assisted radical prostatectomy in locally advanced prostate cancer. Int J Urol. 2018:25:30-5.

24. Quan H, Li B, Saunders LD, Parsons GA, Nilsson Cl, Alibhai A, et al. Assessing validity of ICD-9-CM and ICD-10 administrative data in recording clinical conditions in a unique dually coded database. Health Serv Res. 2008;43: 1424-41.

\section{Publisher's Note}

Springer Nature remains neutral with regard to jurisdictional claims in published maps and institutional affiliations.

Ready to submit your research? Choose BMC and benefit from:

- fast, convenient online submission

- thorough peer review by experienced researchers in your field

- rapid publication on acceptance

- support for research data, including large and complex data types

- gold Open Access which fosters wider collaboration and increased citations

- maximum visibility for your research: over $100 \mathrm{M}$ website views per year

At $\mathrm{BMC}$, research is always in progress.

Learn more biomedcentral.com/submissions 